\title{
'The sooner the better I could get out of there': barriers to higher education access in Ireland
}

\author{
Selina $\mathrm{McCoy}^{\mathrm{a} *}$ and Delma Byrne ${ }^{\mathrm{b}}$ \\ ${ }^{a}$ Economic and Social Research Institute; ${ }^{b}$ Department of Education and Sociology, NUI, \\ Maynooth
}

\begin{abstract}
As economic circumstances in Ireland, as elsewhere, remain difficult and applications for higher education entry reach record numbers, there has been renewed focus on higher education access. This article draws on the findings of a major Irish study which focuses on a group that has not shared in the general trend towards increased higher education participation - the offspring of the 'lower non manual' group. This article draws on the findings of that study to examine the barriers such young people face in accessing higher education. It is based on a combined analysis of 10 years of School Leavers' Survey data and indepth life-history interviews with school leavers whose parent(s) were employed in such non-manual jobs. Overall, the study points to the role of cultural, educational and economic factors shaping the higher education entry patterns of young people. It addition it highlights the importance of examining within as well between class patterns of educational attainment.
\end{abstract}

Keywords: higher education access; social class; non-manual group

\section{Introduction}

As economic circumstances in Ireland, as elsewhere, remain difficult and applications for higher education entry reach record numbers, there has been renewed focus on higher education access. Postponement of labour market entry among school leavers more generally and growing numbers of (young) adults returning to higher education to improve their skills also highlight the issue of access. In this context, identifying which groups fare least well in higher education entry and the potential barriers they face in gaining entry is of central importance. A major Irish study (McCoy et al. 2010a) focuses on a group which has not shared in the general trend towards increased third-level participation - the offspring of the 'lower non-manual' group. ${ }^{1}$ This group largely comprises lower level service workers and accounts for just under $10 \%$ of the Irish population (further details are provided in the methodology section). Young people from this socio-economic group are poorly placed in terms of higher education participation and are also the only social group to have seen a fall in levels of entry over time. This article draws on the findings of that study to examine the barriers such young people face in accessing higher education. It is based on a combined analysis of 10-years of School Leavers' Survey data and in-depth life-history interviews with school leavers whose parent(s) were employed in such

\footnotetext{
*Corresponding author. Email: Selina.McCoy@esri.ie
} 
non-manual jobs. Overall, the study points to the role of cultural, educational and economic factors in shaping the higher education entry patterns of young people.

\section{Theoretical framework}

Young people from 'socio-economically disadvantaged' or 'lower socio-economic backgrounds' have been of particular focus in higher education access research internationally (Breen and Goldthorpe 1997; Shavit, Arum, and Gamoran 2007; Becker and Hecken 2009; McCoy and Smyth 2010), with such disadvantaged groups typically comprising those from working-class backgrounds or unemployed households. Recent research (McCoy et al. 2010a) in the Irish context suggests that the groups faring least well in terms of higher education entry are not confined to those traditionally defined as disadvantaged, but span those from lower whitecollar backgrounds and the sons/daughters of those in largely service sector occupations.

The article draws on two main theoretical perspectives in attempting to understand the low levels of higher education entry among this lower non-manual group. These perspectives played a central role in the design of the research instruments. Cultural approaches, evident in the work of Bernstein, Willis, Villegas, Brown, Lareau, as well as Bourdieu, are at the fore in educational debate. Referred to as 'pushed from behind' approaches (Gambetta 1987), they emphasise mechanisms related to cultural processes, such as norms, beliefs and sub-cultural values, as they shape preferences, expectations and choices. Rational Action Theories (RAT), by and large, do not invoke 'cultural' or 'normative' differences between social classes to explain their differing educational orientations, decisions or outcomes. Rather, such differences are explained with reference to differences in the resources and constraints faced by occupants of social class positions. Essentially, individuals and their families are viewed as acting rationally in the context of their circumstances, as choosing among the varying educational choices available to them on the grounds of their perceptions and evaluations of their costs and benefits and of the perceived probability of their successful achievement. This approach is useful in the current context as educational attainment is seen as a sequence of decisions - decisions which must be examined on a step-by-step basis, rather than solely in terms of highest educational attainment or entry into higher education (as examined by Hillmert and Jacob 2002). The student and his/her parents must make decisions at each stage in the educational process (transition into secondary school, completion of lower secondary, persistence beyond the compulsory schooling-age and so on). While RAT perspectives have typically been adopted to examine decisions within the compulsory school system, this study is concerned with both decisions within the school system and also decisions on leaving school (principally, the decision to pursue higher education). Educational decisions are argued to derive from social background, the value system of the home environment, expectations of success and 'relative risk aversion' (attempts to ensure that children have a position in life that is not worse than their parents), and also from the individual's own preferences and aspirations. 


\section{Hypotheses}

Drawing on these two main theoretical frameworks, the following main hypotheses guide the article:

(1) Young people from lower non-manual backgrounds do not possess the cultural capital necessary to succeed within an educational system geared towards the dominant class.

(2) Occupants of the lower non-manual group do not themselves have experience of higher education and do not have the same expertise to assist their children in negotiating the higher education entry track and hence their children are more reliant on guidance from their school.

(3) Young people from lower non-manual backgrounds are less likely to enter higher education as a result of the higher relative costs of doing so, the greater opportunity cost and the lower likelihood of success.

The following considers the methodology adopted in the article, followed by an overview of some key aspects of higher education in the Irish context and discussion of the results.

\section{Methodology}

This article is based on a mixed method approach, which is considered the 'gold standard' in educational research today. In adopting such an approach, the study combines the strengths of qualitative and quantitative methods to allow a much fuller understanding of the processes underlying higher education entry and nonentry among young people from lower non-manual backgrounds.

The analysis is based on pooled School Leavers' Surveys (nationally representative surveys of young people two years after leaving school) conducted during the 1990s and 2000s by the ESRI. The survey included young people who left the secondary education system in 1997/98, 2002/04, and 2006/07. The sample consists of 3775 leavers from 611 schools. The multivariate analyses of factors influencing their educational attainment employed logistic regression, estimated by maximum likelihood. The statistical methodology takes account of the clustering of students within schools and so the models were estimated using robust standard errors. This method allows for within-cluster correlation of errors, and results in much more conservative standard errors and smaller t-statistics than those in an unclustered model. That is, this method relaxes the requirement that the errors be independent, by allowing them to be correlated within each cluster group (school). This correlation affects only the standard errors and t-statistics but not the estimated coefficients.

The statistical methodology also ensures that the method chosen is adequate to handle the number of potential explanatory variables relative to the sample size. The model-building strategy employed was to fit models for each dependent variable by forward step-wise regression, closely following the methodology employed by Hosmer and Lemeshow (1989). However, variables that are deemed important based on previous research to the outcome in question are also included in the equation. Using this method, explanatory variables are introduced one at a time. Further checks of the model specification are then conducted. A number of 
goodness-of-fit statistics are assessed: the McFadden R-squared and the likelihood ratio chi square statistic. The former is analogous to the familiar R-squared measure of goodness-of-fit, but adapted for logistic regression. It varies between zero, signifying no relationship between the explanatory variables and dependent variable, and one, signifying a perfect model. The likelihood ratio chi square statistic is a measure to evaluate the fit of the model. The odds ratios used to quantify the relationships derive from these models. The overall aim when adopting this strategy is to produce models that include all observed variables known to influence the outcome of interest, without over-fitting the model. Notably, we rely on experience and judgement, balancing a combination of different goodness-of-fit statistics and robustness to the inclusion or exclusion of other variables. In particular, the biggest danger is that a key variable is omitted from a model and that this results in a spurious relationship being reported. For example, the absence of a measure of previous educational attainment from the models may overstate the effects of the variables already in the model.

Logistic regression models estimate the relative influence of a range of objective characteristics (gender, highest parental occupation, ${ }^{2}$ parental educational attainment, regional location and type of school attended ${ }^{3}$ ) on the likelihood that students reach a certain threshold, for example completing secondary education. From these models, it is possible to calculate odds ratios, which express the odds that a person of particular characteristics will complete this benchmark relative to a different case. The reference case in each set of analyses constitutes a male from a semi-unskilled manual background, living in Dublin, whose parents have primary-level education, who attended a community/comprehensive and designated disadvantaged (DEIS) school.

The quantitative analysis, the primary data source for this article, is largely focused on the relative position of different socio-economic groups, defined on the basis of the Census of Population 1986 classification. Within this classification, socio-economic groups range from higher professional workers, employers and managers to semi- and unskilled manual workers. The broad 'non-manual' group, which occupies a mid-way position, is comprised of two main socio-economic groups: intermediate non-manual and other non-manual. These two socio-economic groups have distinct occupational profiles - the former is comprised of a number of relatively high status positions such as senior police officers and lower ranks and government executive officials. In contrast, the latter 'other non-manual' group is dominated by lower level service workers - including bus drivers, barbers/hairdressers and waiters/waitresses. While much existing educational research in the Irish context largely considers the non-manual group as one category, such an approach has concealed important differences between these groups and hidden a pattern of educational attainment among the latter lower non-manual group which is highly disadvantaged (see McCoy et al. 2010a). In both the quantitative analysis and through in-depth interviews with young people of both socio-economic groups, it was clear that the two non-manual groups displayed diverging educational profiles young people from intermediate non-manual backgrounds are considerably more likely to complete secondary education, perform highly in the Leaving Certificate exam and successfully progress to higher education. In this context, this article focuses specifically on the relative experiences of the sons and daughters of lower 
non-manual workers, attempting to unpack the social, cultural and economic factors underlying their low levels of higher education entry.

The qualitative component represents the secondary data source for this article and allows a greater understanding of the barriers to higher education for nonmanual young people. It is based on in-depth interviews with 29 school leavers, 13 of whom with at least one parent employed in lower non-manual occupations and the remaining 16 with parent(s) employed in intermediate non-manual positions, selected by theoretical sample from the 2006 School Leavers' Survey cohort, as detailed above. The framework of the interview schedule was within a life/oral history context. As Thompson (1988) highlights, using a life/oral history framework uncovers the underpinnings of 'the decisions which individuals make' (Thompson 1988, 298). Using this framework allowed the research to focus on the factors which influenced young people's decision-making with regard to their post-school choices. The interviews, taking a semi-structured format, spanned the home and family environments of the participants, their school experiences and engagement with schooling, peer influences, career and educational aspirations and the factors influencing their expectations and plans for the future. The young people were typically 22-23 years of age at the time of interview and had taken a range of postschool pathways, including entry to Post-Leaving Certificate (further education) courses, apprenticeships and entry into the labour market. The interviews were recorded (with their consent) and transcribed verbatim. The data were then analysed using the QSR N6 package to identify emerging themes and the processes underlying the post-school choices of the young people.

\section{Higher education entry in Ireland}

In Ireland, young people enter secondary education at 12 or 13 years of age. Participation in full-time secondary education is compulsory until the age of 16 or until three years of lower secondary education has been completed. The Irish secondary system is comprised of a three-year lower secondary programme, at the end of which students take a nationally standardised examination, the Junior Certificate. Grades achieved in this examination influence the type and level of subjects or programme that students can access at upper secondary. The majority of students who complete upper secondary education take the traditional Leaving Certificate, which includes the Leaving Certificate Established (LCE) and the Leaving Certificate Vocational Programme (LCVP), where students are eligible for entry to higher education. A small proportion of students ( $\% \%$ per annum) take the Leaving Certificate Applied programme (LCA), which offers a general prevocational type curriculum but does not offer direct access to higher education. The higher education system operates on the basis of numerus clausus, whereby applicants for specific courses are ranked in terms of points (grades) with the highestranking candidates offered a college place.

The most recently published data shows a higher education participation rate of over 55\% (McCoy et al. 2010a), representing a dramatic expansion in higher education participation in Ireland (from just 20\% in 1980). While such rapid expansion is impressive by international standards (OECD 2006), it masks continuing social inequality in access and entry to higher education in Ireland. Despite the increase in the overall number of young people entering higher 
education, there remains a persistent under-representation in higher education of young people from disadvantaged backgrounds (O'Connell, Clancy, and McCoy 2006a; O'Connell, McCoy and Clancy 2006b; McCoy et al. 2010a). As illustrated in Figure 1, to a large extent the children of higher professionals and employers/ managers, in particular, have maintained their privileged access to higher education, while other groups such as the children of manual workers and those from unemployed households fare less well.

Furthermore, one group has not shared at all in a general trend towards increased higher education participation, namely the lower non-manual group (McCoy et al. 2010a). This group, which largely comprises lower level service workers ${ }^{4}$ are poorly placed in terms of participation and are the only group to have seen a fall in levels of higher education entry over time. In this article, we will detail the nature of this under-representation and explore the processes underlying the low levels of higher education entry among this group. We take a sequential approach, assessing the relative position of the lower non-manual group across a range of key transitions: completion of secondary education, performance in the Leaving Certificate (upper secondary) examination and application for entry to higher education. Such an approach is particularly warranted given that entry to higher education is predominantly based on performance in the Leaving Certificate examination. This article is unique in assessing the position of this lower non-manual group across this range of key transitions, combining the analysis with qualitative material unpacking the expectations and experiences of this group.

\section{Results}

The article draws on the findings of multivariate quantitative analysis, examining the education patterns of different socio-economic groups, combined with in-depth

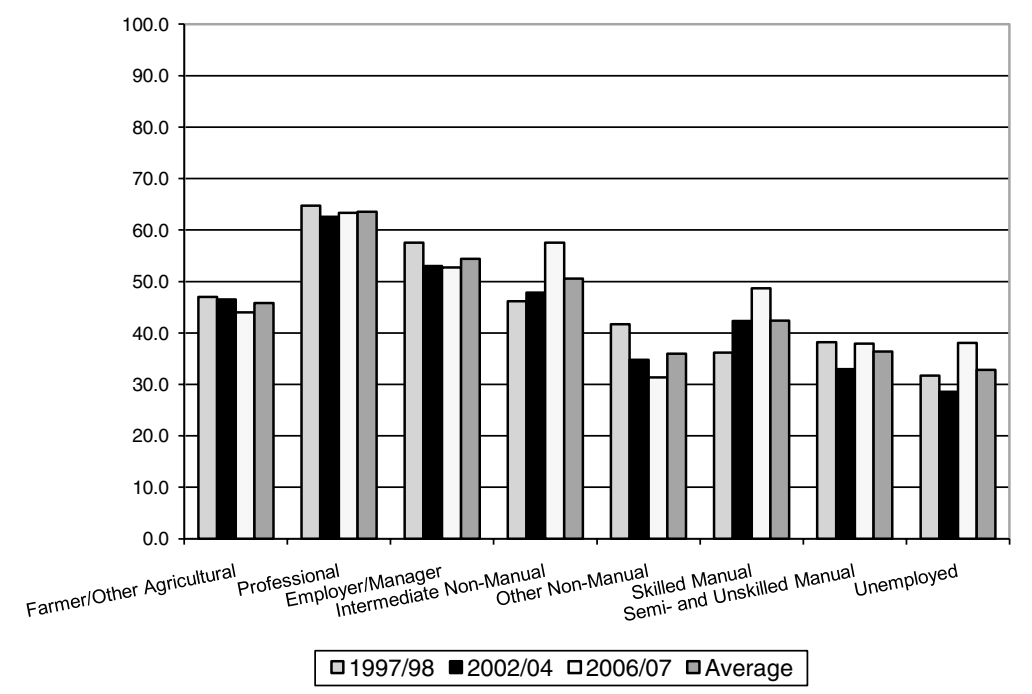

Figure 1. Participation in full-time higher education among secondary school completers by parental socio-economic group. 
interviews comparing the experiences of young people from lower non-manual backgrounds with those of young people from intermediate non-manual backgrounds, a group faring much better in higher education entry. These latter interviews unpack the processes underlying the broader quantitative patterns.

Overall, the study points to three main sets of factors shaping the higher education decisions of this group:

\section{School experiences and processes}

In examining secondary completion, gender differences are notable with females four times more likely to complete secondary education than males. Furthermore, parental education is important, with students whose parents have degree-level education being five times more likely to complete secondary education. We also find that students attending non-DEIS (non-disadvantaged) schools are more likely to complete secondary education than those attending DEIS (disadvantaged) schools, all else being equal. This suggests that a concentration of socio-economic disadvantage has an additional multiplier effect above and beyond the impact of an individual's social background.

As shown in Figure 2, students from higher socio-economic backgrounds have greater chances of completing secondary education relative to the semi-/unskilled manual group: nearly two-and-a-half times for a person from a professional background, almost two-fold for a person from a farming or employer/manager background and over one-and-a-half times for a person from an intermediate nonmanual background. The overall findings suggest that the chances of completing secondary education for the lower non-manual group do not differ significantly from those from skilled manual backgrounds or semi- and unskilled manual backgrounds, the groups traditionally defined as 'disadvantaged' in the Irish context.

Turning attention to the transition from lower to upper secondary education (taking the same approach as in Figure 2), students from higher socio-economic backgrounds are more likely to make the transition from lower to upper secondary: over two-fold for those from professional backgrounds, almost two times for a person from a farming background and one-and-a-half times for a person from an intermediate non-manual background relative to those from a semi-/unskilled manual background. Again, the findings suggest that the chances of making the transition from lower to upper secondary do not vary significantly among those from other non-manual backgrounds, skilled manual backgrounds or semi-skilled manual backgrounds. While not shown here, gender is also influential as the odds of a female making the transition from junior cycle to senior cycle are almost four times higher than that of a male. Furthermore, parental education is important - those whose parents have degree-level education are six times more likely to make the transition than a person with the same characteristics whose parents have primary-level education. The type of school is also important, with persons who attend a nonDEIS school having a greater probability of making the transition from junior cycle to senior cycle than those attending a DEIS school.

In addition to completion of secondary education, a further key determinant of higher education entry in the Irish context is performance in the Leaving Certificate examination, with the vast majority of places awarded on the basis of 'points' achieved in the examination and entry to more 'prestigious' courses demanding 


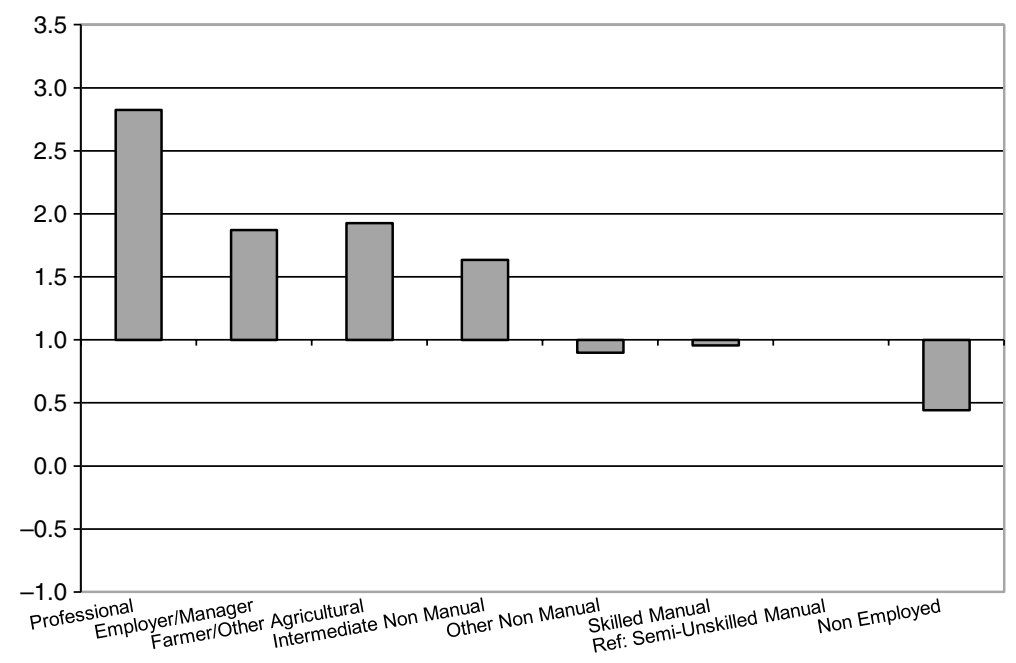

Figure 2. Odds ratios for completion of secondary education.

Note: 3775 Students in 611 Schools; Wald $\mathrm{Chi}^{2}=597.44^{* * *}$; Pseudo $\mathrm{R}^{2}=.17$.

particularly high performance levels. Overall, between 60 and $65 \%$ of school leavers (who completed the Leaving Certificate) achieved two or more 'honours' (grades of A-C on a higher level paper) in this exam over the last 10 years. Across each timepoint, there is no visible gender difference in the proportions attaining two or more 'honours'. However, gender differentials are more apparent when we examine the highest performing group (five or more honours), where females considerably outperform their male counterparts. In 2006/7, for example, while $35 \%$ of females achieved 5 or more 'honours,' just one-quarter of males had performed equally highly.

While secondary education retention and progression patterns are highly patterned by socio-economic background, so too is performance in the Leaving Certificate examination. Those from more 'advantaged' backgrounds are most likely to perform highly in the exam, with those from the professional, employer/ managerial, farming and intermediate non-manual groups most likely to achieve at least two honours in the examination. Again the results point to significant differences between the non-manual socio-economic groups and the position of these two groups relative to other groups. High performance in the Leaving Certificate examination is also more likely for those who attend non-DEIS schools and among those whose parents have degree-level education. Table 1 shows that students from the other non-manual group, while showing a slight relative advantage, do not differ significantly from the semi-skilled/unskilled manual group in their probability of performing highly in the Leaving Certificate examination. Essentially, large proportions of young people from lower non-manual backgrounds are not achieving eligibility; we now turn to the in-depth interviews to understand why this group fare so poorly within secondary education.

In conducting the qualitative interviews, it was apparent that young people who entered higher education typically reported positive orientations towards, and experiences of, their initial education - most simply, they placed a value on 
education and engaged positively with it. Among those that do not progress, this research identifies some important issues around self-belief and aspirations with young people often stating that 'college is not for me.' While these beliefs to some extent stemmed from a more short-term orientation and a necessary priority on earning money in these families and hence an orientation in line with RAT, they also reflected the nature of their previous educational experiences at secondary level. The findings pointed to a greater risk of disengagement from school among this group of young people who reported skipping school, a lack of motivation and misbehaviour which fed into a negative cycle of interaction with teachers. Moreover, this group of young people largely felt that they had been treated unfairly by their teachers and perceived that their teachers held low expectations for them. This highlights the importance of cultural perspectives in understanding educational outcomes. Higher education was perceived as an extension of school for this group and hence to be avoided. Low levels of school completion and poor performance in the Leaving Certificate examination among this group were the result of these often negative school experiences, meaning large numbers were ineligible for higher education.

The results point to large differences in the secondary school experiences of young people from the two non-manual groups, which go some way towards understanding such wide differentials in the proportions achieving eligibility for entry into higher education. It was clear that those who did not progress were much more critical of their teachers and the teaching they had received. Several spoke quite negatively about their school experiences. For some this stemmed from a lack of interest in school activities: 'I had no interest in school; I just did not like school at all, the sooner the better I could get out of there'. For many who found school difficult or uninteresting, their response very much reflected that they had disengaged from school life: 'I wasn't in school that much...it's long hours and very boring some of it. .I skipped school a lot.'

Many of these school leavers expressed a desire for varied teaching techniques and not just copying notes from the board or reading from a book. The respondents spoke about teachers who took different approaches that enabled them to learn better in class. Some were also somewhat dissatisfied with the subjects on offer to them and would have liked a wider range of subjects and more hands-on, practical subjects. A clear distinction was also evident between the higher education entrants and the non-entrants in terms of how subject choice was determined, which may shed some light on differences between the two non-manual groups. The higher education

Table 1. Odds ratio of attaining at least 2 'honours' in the Leaving Certificate.

\begin{tabular}{lc}
\hline Socio-Economic Group & Odds Ratio \\
\hline Higher Lower Professional & 2.557 \\
Employer Manager & 1.910 \\
Farmer/Other Agricultural & 2.459 \\
Intermediate Non-Manual & 1.562 \\
Other Non-Manual & 1.390 \\
Skilled Manual & 1.160 \\
Semi- and Unskilled Manual (reference group) & 1.000 \\
Non-Employed & 0.671 \\
\hline
\end{tabular}

Note: 1803 Students in 425 Schools; Wald $\mathrm{Chi}^{2}=169.98^{* * *}$; Pseudo $\mathrm{R}^{2}=.08$. 
entrant group were happy with the subjects that were on offer, and tended to choose subjects in which they were most likely to achieve high points in the Leaving Certificate examination. In contrast, the others did not tend to adopt this tactic. In fact, some of the other non-manual students felt that they had been forced to choose lower subject levels, and were often dissatisfied with the subjects on offer.

Some of the young people interviewed felt that teachers made a distinction between those who would progress to higher education and who would not, which then influenced how they were treated by teachers. What was particularly interesting was that some of this group had applied to go to higher education, but also had alternative education or training pathways earmarked if they did not gain access or did not obtain their higher education preference. As Sharon (a pseudonym) explained:

...they had their favourite kids, if they thought like you were academic like they'd love you but if they thought you were a bit laid back they'd just leave you.

It was also evident that those, particularly males, from the other non-manual group were much more likely to fall into cycles of negative interaction, poor behaviour and failing to take school seriously. This had led to a process of gradual disengagement from schoolwork and a desire to 'get away' from education. This raises crucial issues around school climate, and has many parallels to the findings of a longitudinal study of secondary students in Ireland (see Smyth et al. 2006). It points to the importance of promoting a positive school and classroom climate, where good relations between students and staff are fostered, positive reinforcement is promoted and students are encouraged to become involved in school both at formal (student councils, for example) and informal (sports and extracurricular) levels.

\section{Information and advice}

The second issue shaping choices is that of career guidance or advice. In the UK context, one study noted that guidance was not equally available to all students (Lee and Ekstrom 1987), while research in the Irish context suggests young people are often highly reliant on external sources of advice in making post-school choices (McCoy et al. 2006). In analysing the qualitative interviews, it is clear that members of the intermediate non-manual group who successfully progressed to higher education were much more positive about the career guidance they received while at school and the expectations school personnel held for them. They spoke very highly about the career guidance in their schools and felt they had ample information and advice about their available options. They all commented that help was available in relation to the CAO (college application) form if required; this included filling out mock CAO forms. Other career guidance included one-on-one meetings with the career guidance teacher to discuss available options, aptitude tests, attending careers days as well as open days in individual colleges and universities. In some instances, past pupils returned to their school to talk about college life, and guest speakers were invited to the schools to talk about particular career paths. Overall, they expressed satisfaction with the guidance support they received, as Daragh (from an intermediate non-manual background) states 'everything I wanted she [the guidance 
counsellor] got for me, [the same for my] friends as well, anything they wanted they were given information about.' Similarly, Eamon comments:

...there was a great career guidance teacher. . he put in the time for you and he wasn't really relevant [interested in] how much money he was getting or anything like that; he didn't want anything from it. But yet any of the information that we wanted was given to us, [he] told us our options and...he always asked previous students who went to college to come back and talk to the fifth and sixth years about their experience in college.

In contrast, members of the other non-manual group were often directed away from higher education, perceived that they were not considered higher education 'material' by teachers and guidance staff and, where they did get information on higher education, it was often about the mechanics of applying rather than discussing what they might like to do. As a result, a number of (particularly male) members of the other non-manual group left school unsure about what they wanted to do and clearly lacking any real direction. It can also be noted that for the intermediate non-manual group, even where guidance was lacking, they were able to rely on the assistance of parents who were themselves familiar with the CAO process and higher education in general (having themselves participated). The other non-manual group, in contrast, are much more reliant on school-based advice, hence signifying the importance of comprehensive advice at school and a supportive environment where expectations are high. Variable access to guidance and judgements as to their suitability for higher education meant that many of the young people from lower non-manual backgrounds did not feel well-equipped to face higher education choices or did not feel that was an option for them. As Sharon, for example, observed: 'I remember my class tutor told me in sixth year that I'd amount to nothing and I'd fail me Leaving Cert.' She went on to explain:

... if they thought you were an honours student they'd like do everything for you but if they thought you weren't good they'd just kind of leave you there do you know that way, I don't think they pushed us enough, do you know that kind of way, they just kind of left some of us.

It is interesting to note that others, such as Charlie, would have liked more encouragement to consider higher education, feeling that they were not really challenged to consider this as a realistic option for them:

So I settled for the apprenticeship, and like I said, I know that if I had of been pushed to do something, or if I had of been kept interested, I most likely would have gone to college.

Others noted that only the 'higher (stream) classes' were given the opportunity to attend open days, which they felt was unfair to other students who may have an interest in progressing to higher education. This was viewed as sending out a message to students that certain 'brainier' students were destined to go to higher education, but this option was not open to all students.

In reflecting on the advice and support from parents, there was evidence among the lower non-manual group that their parents were highly supportive in 'whatever they wanted to do.' Many did not push them in a particular direction, 'they never put pressure on me.' There was evidence of what has been referred to as a working-class discourse of 'child as expert' in the UK context (Reay and Ball 1998). Within the 
school context, in contrast, it appeared that for many the push was, if anything, 'diversionary,' focusing on alternative post-school options, like further education (Post-Leaving Certificate [PLC] courses), which were considered more 'appropriate,' required fewer 'points' in the Leaving Certificate exam and were judged to be a less risky option. It appeared that school personnel framed the choices of the lower nonmanual students, in the process contributing to the reproduction of existing social class differentiation. In Sharon's school, large numbers progressed to further education courses, many doing so because they felt they would not get sufficient 'points' for higher education:

... a lot of them went on to do PLC courses...a lot of them were worried about the points for the, you know the way you have the big points [for higher education courses]...I think they all kind of put their name down for the PLC because they knew they'd kind of more or less get that... So that was kind of the preferred choice.

Returning to the School Leavers' Survey data, when we consider college application rates across social groups, it is clear that even among those completing upper secondary education, rates of application vary widely across groups and further highlight the differential level of expectation across socio-economic groups. As illustrated in Figure 3, those from other non-manual backgrounds are the group least likely to apply for a higher education place, with just over two-thirds of young people from this group applying, a pattern which is somewhat lower than the application rates for the manual groups and substantially lower than the rate of application for the intermediate non-manual group. Almost 90\% of those from professional backgrounds apply for a place in higher education, alongside $86 \%$ of those from a farming background. The position of the other non-manual group is alarming: we have seen large numbers of these young people not eligible for higher education entry as a result of drop-out from secondary level, now coupled with low levels of higher education application among those eligible for entry.

This research highlights how the availability of information and advice on higher education is a key factor in the decision to enrol. This is very much in line with international research which shows that students who have knowledge of the college process, who develop plans to attend college earlier and who participate in college 'outreach' programmes are more likely to attend college (Cabrera and La Nasa 2001; Lindholm 2006). In many ways, this group of young people were far more reliant on the advice and support from their school in making these decisions, since few had parents with experience of higher education and their siblings and peers were also not generally familiar with the 'process.' Indeed it is argued elsewhere that the information that is needed by lower social classes is in itself more complex than that needed by their middle-class counterparts (Hutchings 2003). This relates to the greater diversity of pathways into higher education for young people from underrepresented groups - making the system more complex than for their middle-class counterparts entering higher education through more traditional, well-established and direct entry routes. However, findings show that for the lower non-manual group career guidance was variously absent, only focused on certain groups of students (such as the 'honours' class), narrowly focused or directed them away from higher education altogether towards a more 'appropriate' place in the social order. Furthermore, some young people felt they would have liked more help in evaluating the range of post-school options, rather than just receiving information. 


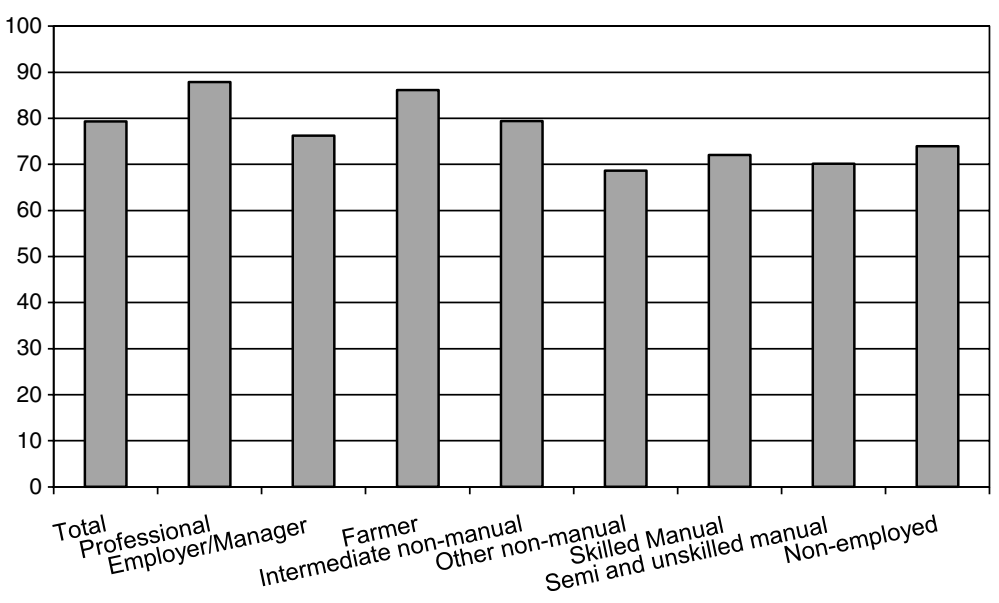

Figure 3. Proportion of school leavers who completed Leaving Certificate who applied to enter higher education by parental socio-economic group (2007).

\section{Financial considerations}

Financial issues also influenced the post-school choices of this group of school leavers and these highlight the value of the RAT approach in understanding higher education entry patterns. For some, the financial commitment to study was perceived as too great or would exert too much hardship for themselves and their families. Many felt that they would not have been eligible for financial support (and in fact this group have seen the sharpest fall-off in grant receipt levels over time - McCoy et al. 2010b), or if eligible, they felt the support would not have been adequate. They did not want the 'broke' student lifestyle; 'you always hear of student life, they've no money and all, I just couldn't.' Again there was evidence of insufficient information and understanding of the system of financial supports and the costs entailed. The research also found that perceived financial barriers also framed the aspirations of these young people and, among those who were eligible to apply, perceived financial barriers often shaped that final decision not to attend.

Finally, it was clear that the pull of the (then booming) labour market represented an important motivating factor for males, particularly those from other non-manual backgrounds. In many ways they could be seen as behaving 'rationally' in the context of alternative opportunities. It meant that leaving school without further education plans was an easy option and did not seem to be challenged by teachers (and was even encouraged in some cases). While some of these young people now reflect on these choices with some regret and see themselves as more vulnerable than collegeeducated peers, it seems that teachers and Guidance Counsellors should place a greater emphasis on highlighting the implications of taking various post-school options in the longer term.

Returning to the survey data, for those who chose not to pursue higher education, respondents were asked to indicate the reason(s) behind that decision. Respondents were most likely to indicate that the reason for not seeking entry into higher education related to the intrinsic value of higher education - they indicated that 'they weren't interested.' This quantitative finding echoes the discussions around higher education decisions in the qualitative interviews where young people spoke 
about higher education as being 'not for me.' However, there was also evidence that working and earning at the earliest opportunity was an important motivation for some young people. In line with research in the UK context (for example, Connor 2001), financial issues clearly figure in young people's choices - a desire to earn money and/or concerns over being able to afford higher education were indicated by a considerable share of over one-third of young people who did not apply for higher education. Other recent research (McCoy et al. 2010b) highlights further issues around the financial barriers to higher education participation. This study again highlighted that inadequate provision of information about the possible sources of income available could potentially dissuade certain students from applying to higher education (2010b, 73). Difficulties also arose for young people who were unclear over the likely costs attached to attending higher education. This research also pointed to the financial pressures faced by more disadvantaged groups attending higher education and the difficulties faced by those relying on state grant support which has declined in value over time. Furthermore, financial strain among more disadvantaged groups had implications for their opportunity to fully participate in college life, that is, to participate in the non-academic social and cultural dimensions of college life as well as the academic.

Overall, in returning to the hypotheses guiding the article and the two main theoretical approaches identified, it is clear that both approaches contribute to our understanding of social differentiation in higher education access, particularly among this non-manual group. First, cultural approaches emphasise mechanisms related to cultural processes, such as norms, beliefs and sub-cultural values, as they shape preferences, expectations and choices. The findings of this study, in drawing on both quantitative and qualitative methodologies, clearly point to the enormous value of such 'cultural' explanations in understanding processes of educational disadvantage among the other non-manual group. For many of these young people, negative school experiences and disengagement from the dominant-class school culture, interlinked with lower aspirations, led to secondary school pathways and transition decisions which were uncertain and constrained. Many failed to achieve eligibility for higher education and among those who were eligible the discourse of higher education was, for some, alien and foreign and one which had not necessarily been promoted at school. Where they did succeed in progressing to higher education, aspirations were lower and higher status courses and institutions were not seen as a realistic option for them.

The second theoretical approach, the rational action perspective, places greater emphasis on the resources and constraints faced by occupants of different social class positions. Distance from social origin and the desire to avoid social demotion mean that patterns of educational attainment across different social groups could be comparable given their differing positions of origin. Again the results of the study lend support to this perspective: young people from other non-manual backgrounds typically come from non-higher education origins and the social distance of going to higher education (and particularly to a university) is considerably greater than for a young person from a professional background (and also an intermediate non-manual background). For many of these young people, the pull of the booming labour market offered an acceptable post-school pathway. The pressure to pursue higher education as a means of avoiding social demotion was less than for other social groups and they also framed the costs and benefits of education differently. Finally, 
in line with greater distance from social origin and the lower likelihood of success (evident in higher drop-out rates, for example), this group could be seen as acting rationally in not pursuing the higher education option.

Both cultural and rational action perspectives offer valuable insights into the processes explaining both socio-economic patterns in educational attainment and within-class differences. The complex interplay of economic constraints, cultural context and knowledge of the system and early educational experiences, clearly differentially frames the educational choices that different families can and will make.

\section{Discussion}

This article has made a contribution to the higher education access literature in two important respects. Firstly, the benefits of higher education participation to the individual and to society are well-established. However, in the Irish context much less is known about what shapes young people's post-school choices and the decision to enrol in higher education. From the findings of this research, it is clear that higher education entry must be viewed as the outcome of a longer-term process of educational engagement. Educational experiences, particularly in secondary school, play a central role in the longer-term educational trajectories of young people. These findings have some parallels in the UK context, where Raffe et al. (2006), for example, find that class differences in entry to higher education can largely be attributed to class differences in achieving the qualifications for entry to higher education (1). Overall, the results point to large differences in the secondary school experiences of young people from the two non-manual groups, which go some way towards understanding such wide differentials in the proportions achieving eligibility for entry into higher education. However, it would be misleading to argue that such differences emerge at secondary level, as research also clearly demonstrates that social differentiation in educational outcomes is evident at much earlier stages - early in primary level education for example (see Smyth and McCoy 2009).

Even among young people achieving eligibility for higher education, notable differences emerge across groups in their patterns of post-school choices and progression to higher education. At this point, in particular, we see a fall-off in the pursuit of higher education among young people from lower non-manual backgrounds. It is clear that information plays a central role. Information about the college application process, assistance with discerning among the range of choices on offer and critically assessing where there interests and aptitudes might best lie seems central not just to entry but to successful college engagement and completion. Lack of information about the financial aspects of college, the supports available and eligibility for these supports, and the likely costs of college are especially problematic barriers for the children of lower non-manual workers. If anything the financial barrier is likely to have become more pressing of late as recent economic conditions are likely to further restrict the ability of these and other students to fund their studies through part-time employment. The current economic situation is also likely to curtail the ability of their parents, situated in vulnerable economic sectors, to support their children through college and increase the pressure on these young people to forego college and seek employment. 
This article makes a second notable contribution to the literature on higher education access. Much of the literature has focused on disparities in higher education participation across broad socio-economic groups, often pitched in terms of the differential experiences of those variously classified as 'disadvantaged' or 'working class' relative to those from more 'professional' or 'middle-class' backgrounds. ${ }^{5}$ It is clear that this study provides new insights into important within-class processes operating and points to the need to reconsider the definition of disadvantaged groups, as also highlighted by Bernard (2002) in the Irish context. In the UK, Reid (1998) argues that the definition of the working class is no longer the outmoded image of the male industrial labourer, but rather low paid casualised service workers (among others) represent the contemporary working classes. This article highlights the importance of moving beyond such inter-class studies to a more nuanced analysis exploring patterns both within and across classes.

\section{Notes}

1. This group is also known as lower services, sales and clerical or lower white-collar workers (European Socio-economic Classification [ESeC]).

2. A dominance approach is used (see Erikson 1984), whereby if both parents are in employment, the higher social class of the mother or father is assigned to the family.

3. There are four main school types in secondary education - secondary, community, comprehensive and vocational schools. In addition, students who attended a school deemed to have a high concentration of students from disadvantaged backgrounds under the Delivering Equality of Opportunity in Schools programme (DEIS), 2005, are also identified.

4. Occupations such as chefs, bus drivers and hairdressers.

5. Shavit, Arum and Gamoran (2007), for example, examine the extent of inequality in eligibility for higher education and entry to higher education across 15 countries. As with much research in this area, inequality is measured in terms of the differences between those in professional/managerial classes and the skilled working class, thereby offering little insight into the relative experiences of 'intermediate' groups, such as the non-manual category.

\section{Notes on contributors}

Dr Selina McCoy is a senior researcher at the Economic and Social Research Institute, Dublin. She has worked extensively on higher education issues, particularly access to higher education and student retention. She has a strong interest in gender and social class inequality in educational outcomes, with her research spanning primary, post-primary and post-school sectors. She is currently leading the Leaving School in Ireland programme of research examining how school leavers are faring in the current climate.

Dr Delma Byrne is a Lecturer at the Departments of Sociology and Education, National University of Ireland Maynooth (NUIM), Ireland. Her key research interests focus on social stratification in education and the labour market. This work spans examination of inequality at primary, second-level and higher education as well as post secondary education and training; transitions between education and the labour market, and the evaluation of educational interventions. She is current co-coordinator of the Equalsoc/RC28 Research Group on 'Effectively Maintained Inequality: a Cross National Assessment of Educational Inequality'. 


\section{References}

Becker, R., and A.E. Hecken. 2009. Why are working-class children diverted from universities? An empirical assessment of the diversion thesis. European Sociological Review 25, no. 2: 233-50.

Bernard, J. 2002. Promoting access to higher education and identifying access students: How useful is research on participation by socio-economic group? International Studies in Sociology of Education 16, no. 1: 19-35.

Breen, R., and J. Goldthorpe. 1997. Explaining educational differentials - Towards a formal rational action theory. Rationality and Society 9, no. 3: 275-305.

Cabrera, A.F., and S.M. La Nasa. 2001. On the path to college: Three critical tasks facing America's disadvantaged students. Research in Higher Education 42, no. 2: 119-49.

Connor, H. 2001. Deciding for or against participation in higher education: The views of young people from lower social class backgrounds. Higher Education Quarterly 55, no. 2: 204-24.

Department of Education and Science. 2005. Delivering equality of opportunity in schools: An action plan for educational inclusion. Dublin: The Stationery Office.

Erikson, R. 1984. Social class of men, women and families. Sociology 18, no. 4: 500-14.

Gambetta, D. 1987. Were they pushed or did they jump? Individual decision mechanisms in education. Boulder: Westview Press.

Hillmert, S., and M. Jacob. 2002. Social inequality in higher education: Is vocational training a pathway leading to or away from university? European Sociological Review 19, no. 3: 319-34.

Hosmer, D.W., and S. Lemeshow. 1989. Applied logistic regression. New York: Wiley.

Hutchings, M. 2003. Information, advice and cultural discourses of higher education. In Higher education and social class: Issues of exclusion and inclusion, ed. L. Archer, M. Hutchings, and A. Ross, 97-118. London: RoutledgeFalmer.

Lee, V.E., and R.B. Ekstrom. 1987. Student access to guidance counselling in high school. American Educational Research Journal 24, no. 2: 287-310.

Lindholm, J.A. 2006. Deciding to forgo college: Non-college attendees' reflections on family, school, and self. Teachers College Record 108, no. 4: 577-603.

McCoy, S., D. Byrne, P.J. O’Connell, E. Kelly, and C. Doherty. 2010a. Hidden disadvantage? A study of the low participation in higher education by the non manual group. Dublin: Higher Education Authority.

McCoy, S., E. Calvert, E. Smyth, and M. Darmody. 2010b. Study on the costs of participation in higher education. Dublin: Higher Education Authority.

McCoy, S. and E. Smyth, 2010. Higher education expansion and differentiation in the Republic of Ireland. Higher Education. http://www.springerlink.com/content/bh1362574 42p51q0/.

McCoy, S., E. Smyth, M. Darmody, and A. Dunne. 2006. Guidance for all? Guidance provision in second-level schools. Dublin: ESRI.

O'Connell, P.J., D. Clancy, and S. McCoy. 2006a. Who went to college in 2004? A national survey of entrants to higher education. Dublin: Higher Education Authority.

O'Connell, P.J., S. McCoy, and D. Clancy. 2006b. Who went to college? Socio-economic inequality in entry to higher education in the Republic of Ireland in 2004. Higher Education Quarterly 60, no. 4: 312-32.

OECD. 2006. Higher Education in Ireland. Paris: OECD.

Raffe, D., L. Croxford, C. Iannelli, M. Shapira, and C. Howieson. 2006. Social class inequalities in education in England and Scotland (p. 40). Edinburgh: CES Briefing No.

Reay, D., and S.J. Ball. 1998. "Making their minds up": Family dynamics of school choice. British Educational Research Journal 24, no. 4: 431-48.

Reid, I. 1998. Class in Britain. Cambridge: Polity Press.

Shavit, Y., R. Arum, and A. Gamoran, eds. 2007. Stratification in higher education: A comparative study. California: Stanford University Press.

Smyth, E., A. Dunne, S. McCoy, and M. Darmody. 2006. Pathways through the junior cycle: The experiences of second year students. Dublin: ESRI.

Smyth, E., and S. McCoy. 2009. Investing in education: Combating educational disadvantage. Dublin: ESRI and Barnardos.

Thompson, A. 1988. The oral history reader. London: Routledge. 